\title{
Palliation of Malignant Esophageal Obstruction and Fistulas with Metallic Stents: A Tertiary Center Experience
}

\author{
Hana'a Tashkandi*, Nisar Haider Zaidi, Abdulrehman Sibiani \\ Department of Surgery, King Abdulaziz University, Jeddah, Saudi Arabia \\ Email: "hanaa.tashkandi@gmail.com,drnhzaidi@hotmail.com
}

Received 18 March 2016; accepted 24 April 2016; published 27 April 2016

Copyright (C) 2016 by authors and Scientific Research Publishing Inc.

This work is licensed under the Creative Commons Attribution International License (CC BY). http://creativecommons.org/licenses/by/4.0/

(c) (7) Open Access

\section{Abstract}

Background: To determine the usefulness of metallic stent in advanced oesophageal malignancies. Methods: In a retrospective study conducted at the Endoscopy Unit of King Abdulaziz University Hospital, patients underwent stent placement, with or without palliative radiotherapy for inoperable esophageal cancer, during the period spanning January 2010 through December 2014. Ethical approval for this study was granted by the King Abdulaziz University Research Ethics Committee. Data were collected from the electronic database of the hospital. All patients underwent OGD before stenting to know site of tumor, length of tumor and degree of stricture. Barium meal and CT scan was also done in some cases to know exact characteristics of tumor. Stent was selected more than $2 \mathrm{~cm}$ longer than the length of tumor. Self expanding metallic stents were used in all cases. Confirmation of proper placement of stent was done using fluoroscopy. Complications post stenting were analysed. Results: A total of 15 cases were studied. Males were $53.3 \%$ while females were $46.7 \%$. Youngest patient was $39 \mathrm{yr}$ old and eldest was 79 years with mean 64.93 years. Mean height was $159.73 \mathrm{~cm}$ and mean weight 54.98 kilogram. Co-morbidities like DM was $20 \%$, DM with HTN was $6.7 \%$, bronchial asthma $13.3 \%$ and DM with HTN with IHD and Renal implant in $6.7 \%$. Diagnosis at admission was esophageal squamous cell carcinoma in $33.3 \%$, esophageal adeno-carcinoma in $53.3 \%$, gastric cancer in $6.7 \%$, tracho-esophageal fistula in $6.7 \%$. Stage 3 was $13.3 \%$, and stage 4 was $86.7 \%$. Surgical resection and palliation was done in $14.2 \%$, and only palliation was done in $\mathbf{9 2 . 9 \%}$ of cases. SEMS were used in all patients and majority had Niti-S stent placed in $73.3 \%$ and Wallflex in $13.3 \%$ and Ultraflex in $6.7 \%$ and Boston in $6.7 \%$ cases. Dysphagia was Indication of stenting in $100 \%$ of cases and stricture in $57.1 \%$ and stricture and recurrent aspiration in $\mathbf{4 2 . 9 \%}$. Post stenting complications were early in $20 \%$ and late in $40 \%$. Tumor ingrowth was in $20 \%$, GERD in $20 \%$, Mild chest pain and discomfort in $10 \%$, stent migration in $10 \%$, fistula formation in $10 \%$, chest pain and GERD in $10 \%$, and aspiration and pneumonia in $20 \%$. Conclusions: Self expanding metallic stents are invaluable in advanced oesophageal can-

\footnotetext{
*Corresponding author.
}

How to cite this paper: Tashkandi, H., Zaidi, N.H. and Sibiani, A. (2016) Palliation of Malignant Esophageal Obstruction and Fistulas with Metallic Stents: A Tertiary Center Experience. Surgical Science, 7, 199-205. 
cer for palliation and alleviation of symptoms and better quality of life. Patients prior to chemoradiotherapy may get benefit of stenting making oesophageal passage patent which may otherwise get occluded by edema caused by radiotherapy.

\section{Keywords}

\section{Oesophageal Cancer, Metallic Stent}

\section{Introduction}

Most cases of malignant esophageal obstruction and fistula are caused by primary esophageal cancers [1] [2]. Although there have been recent developments in cancer therapy, many patients unfortunately present with esophageal neoplasms at an incurable stage. At this stage, only palliative treatment can be offered to relieve patients of dysphagia and cough - the most common symptoms in these patients [3].

Surgery has been reported as the best curative treatment for patients with localized esophageal cancer, as it has a clear impact on patients' survival. However, esophageal resections are associated with morbidity and mortality. Perioperative surgical complications are mostly caused by anastomotic leaks, a finding that has been reported in 5\% - 18\% after esophagectomy [4]-[6]. These complications are life-threatening medical emergencies, with a mortality rate of up to 30\% [7]. In patients who present minor leaks without sepsis, conservative treatment can be offered but in cases with major disruptions, a risky reoperation required, which is associated with long hospital stay. Several techniques have been proposed in order to avoid surgical repairs in patients with esophageal leaks. These include endoscopic techniques such as clipping [8] or fibrin glue application [9]; however, these treatment methods have not been proven effective. Endoscopic laser therapy, electric cautery and stent may be helpful in improvement of symptoms but metallic stents have shown to be more effective [10].

The use of stents in patients with esophageal leaks, strictures or perforation has been shown to produce good results in general. Initially, self-expandable plastic stents (SEPS) were utilized, but migration was a major complication associated with this technique [11]-[15]. The use of other types of stents, including partially covered self-expanding metal stent (PCMS) and fully covered self-expanding metal stents (FCMS) have produced good results; however, these techniques are also potentially associated with complications [16]-[19].

This study is an attempt to describe our experience with stenting in patients with esophageal cancers at King Abdulaziz University Hospital.

\section{Methods}

In a retrospective study conducted at the Endoscopy Unit of King Abdulaziz University Hospital, patients who underwent stent placement, with or without palliative radiotherapy for inoperable esophageal cancer, during the period spanning January 2010 through December 2014. Ethical approval for this study was granted by the King Abdulaziz University Research Ethics Committee. Data were collected from the electronic database of the hospital. These included demographic and clinical data.

Procedure of placement of stent. All patient underwent OGD before stenting to know site of tumor, length of tumor and degree of stricture. Barium meal and CT scan was also done in some cases to know exact characteristics of tumor.Stent was selected more than $2 \mathrm{~cm}$ longer than the length of tumor. Self expanding metallic stents were used in all cases. Confirmation of proper placement of stent was done using fluoroscopy. Complications post stenting were studied.

The data were analyzed using the Statistical Package for the Social Sciences (SPSS Inc., IBM, New York, US), version 22. Simple descriptive statistics were used to define the characteristics of the study variables through a form of counts and percentages for the categorical and nominal variables while continuous variables are presented by means and standard deviations.

\section{Results}

A total of 15 cases were studied. Males were 53.3\% while females were $46.7 \%$. Youngest patient was 39 yr old 
and eldest was 79 years with mean 64.93 years. Mean height was $159.73 \mathrm{~cm}$ and mean weight 54.98 kilogram. Co-morbidities like DM was 20\%, DM with HTN was 6.7\%, bronchial asthma $13.3 \%$. and DM with HTN with IHD and Renal implant in 6.7\%. Diagnosis at admission was esophageal squamous cell carcinoma in 33.3\%, esophageal adeno-carcinoma in 53.3\%, gastric cancer in 6.7\%, tracho-esophageal fistula in 6.7\%. Histopathology of the mass is described in Figure 1. Site of mass is described in Figure 2. Figure 3 shows gross description of mass. Stage 3 was $13.3 \%$, and stage 4 was $86.7 \%$. Surgical resection and palliation was done in $14.2 \%$, and only palliation was done in $92.9 \%$ of cases. SEMS were used in all patients and majority had Niti-S stent was placed in $73.3 \%$ and Wallflex in $13.3 \%$ and Ultraflex in $6.7 \%$ and Boston in $6.7 \%$ cases. All except one had emergency stenting. There was no perforation. One had esophageal-pleurofistula which was sealed. One aspiration pneumonia, two cases of migration of stent. Chest pain was in three cases and gastro-esophageal reflux in four cases. There was one case of sepsis after stent who was recovered later. All were followed up to 18 months. Improvement of symptoms was noticed in all patients.

Dysphagia was Indication of stenting in $100 \%$ of cases and stricture in $57.1 \%$ and stricture and recurrent aspiration in $42.9 \%$. Post stenting complications were early in $20 \%$ and late in $40 \%$. Tumor ingrowth in $20 \%$, GERD in 20\%, Mild chest pain and discomfort in 10\%, stent migration in $10 \%$, fistula formation in $10 \%$, chest pain and GERD in 10\%, and aspiration and pneumonia in 20\% (Figure 4).

\title{
Histopathology
}

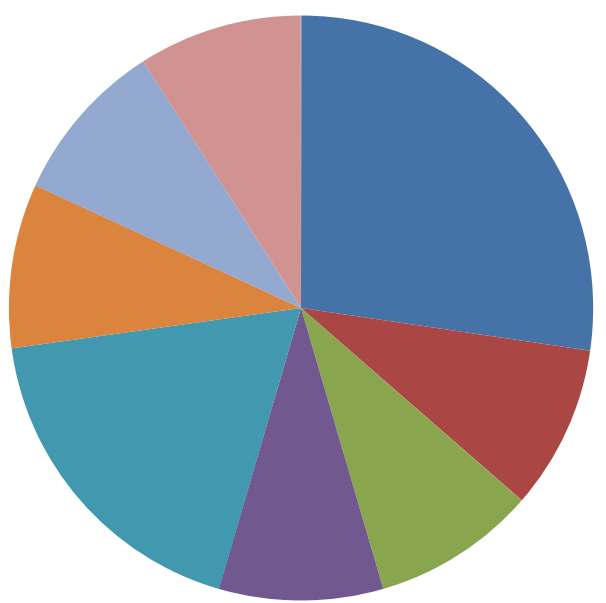

\author{
Adeno CA \\ Mod. Diff.adenoca \\ well diff keratinizing SCC \\ Signet ring adenoca \\ - invasive adenoca \\ poorly diff adenoca \\ - SCC Esophagus \\ Squamous cell CA
}

Figure 1. Histo-pathology.

\section{site of mass}

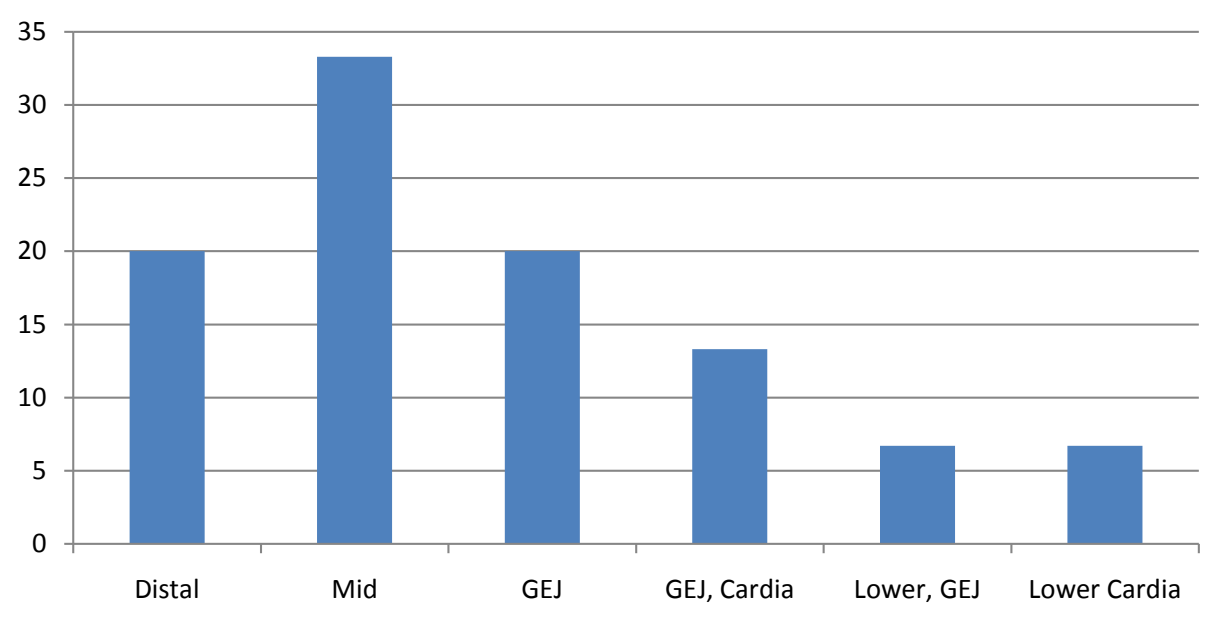

Figure 2. Site of mass. 


\begin{tabular}{lll}
\hline Gross description & $\mathrm{n}$ & $\%$ \\
\hline fungating mass at $20 \mathrm{~cm}$ & 1 & 7.7 \\
\hline tumor at distal esophagus extending $20 \mathrm{~cm}$ from GEJ & 1 & 7.7 \\
\hline mass at $28 \mathrm{~cm}$ down to the cardia & 1 & 7.7 \\
\hline deep ulcer at $20 \mathrm{~cm}$ and TEF & 1 & 7.7 \\
\hline large fungating mass at $22 \mathrm{~cm}$ & 1 & 7.7 \\
\hline large tumor at distal esophagus \&GEJ & 1 & 7.7 \\
\hline fungating mass at $36 \mathrm{~cm}$ extending to cardia & 1 & 7.7 \\
\hline mass at $34 \mathrm{~cm}$ & 1 & 7.7 \\
\hline obstructing lession at $24 \mathrm{~cm}$ & 1 & 7.7 \\
\hline mass distal esophagus extending to cardia & 1 & 7.7 \\
\hline mass at $36 \mathrm{~cm}$ extending to GEJ & 1 & 7.7 \\
\hline mass at $29 \mathrm{~cm}$ extending to GEJ & 1 & 7.7 \\
\hline large fungating mass st distal esophagus & 1 & 7.7 \\
\hline
\end{tabular}

Figure 3. Gross description.

\begin{tabular}{llll}
\hline Complications post stenting & & Count & $\%$ \\
\hline Total & & 15 & 100.0 \\
\hline \multirow{3}{*}{ Complications Post Stent } & Early & 3 & 20.0 \\
\cline { 2 - 4 } & Late & 6 & 40.0 \\
\cline { 2 - 4 } & No & 6 & 40.0 \\
\hline \multirow{4}{*}{ Complications Post Stent } & tumor ingrowth & 2 & 20.0 \\
\cline { 2 - 4 } & GERD & 2 & 20.0 \\
\cline { 2 - 4 } & mild chest pain, discomfort & 1 & 10.0 \\
\cline { 2 - 4 } & stent migration, patient re-stented again after 1 week & 1 & 10.0 \\
\cline { 2 - 4 } & migration, fistula formation & 1 & 10.0 \\
\cline { 2 - 4 } & chest pain, GERD & 1 & 10.0 \\
\cline { 2 - 4 } & aspiration and pneumonia & 2 & 20.0 \\
\hline
\end{tabular}

Figure 4. Post stenting complications.

\section{Discussion}

Oesophageal cancer is a debilitating disease with survival of $10 \%$ - 15\% [20]. High mortality is due to late presentation. More than half of them present at the stage when they are in-operable [21]. Stenting of these patients relieve their symptoms, offer better quality of life. Different types of stents are available like, self-expanding plastic stent; retrievable stent, fully covered, self-expanding metal stents; and self expandable, biodegradable stents that allow passage of food inside the stent. Esophageal SEMS can be furtherclassified based on (a) covering (partially versus fully covered), (b) alloy material (nitinol (alloy of 55\% nickel and 45\% titanium) versus surgical steel versus plastic polyvinyl), (c) function (fully patent versus antireflux), and (d) biodegradability.

Wallflex are SEMSs which are fully and partially covered stent. Unlike other stents, thefully covered. There is a purse string Teflon coated polyester suture at the proximal end which helps in stent repositioning or removal. It has flared ends which decrease migration byanchoring the stent. Niti-S has a double-layer, an inner polyurethanelayer to prevent tumor penetration and an outernitinol wire tube to fix mesh of thestent towall. We used Niti-S mainly in our study. SEMS are delivered in a compressed form, with a small diameter which increases after deployment. Some are preloaded onto the delivery system, and others require loading. They require delivery systems with radio-opaque markers at ends.

In our study males were $53.3 \%$ while females were $46.7 \%$. with mean 64.9 years which is similar to Dong et al. where males were $73.6 \%$ and females $26.4 \%$ and mean age 66.3 years [22]. Dysphagia is the commonest symptom in our study where it was present in all cases which is similar to Katsanos et al. and Park et al. [23] 
[24]. Dysphagia was found to be in $70 \%$ of cases of Brierley et al. [25]. Stage 4 was in $86.6 \%$ and stage 3 was in $13.3 \%$ in our study, while in study by Dong et al. stage 3 was in $67 \%$ and stage 4 in $33 \%$. This difference is because our patients were referred to us in late stage as most of them were from remote areas.

\section{Complications}

Post stenting complications in our study were early in $20 \%$ and late in $40 \%$ While early complications were relatively uncommon in study by Johnson et al., Homann et al. and Lowe et al. but delayed complications were $53 \%-65 \%$ of patients [26]-[29]. Tumor ingrowth in our study was 20\%, while it was 13\% by Yakoub et al. [28] and 12.1\% in Dormann et al. study [30]. GERD in 20\%, Mild chest pain and discomfort in 10\%, stent migration in $10 \%$, while Yakoub et al. reported migration rate of $6 \%$ and $6 \%$ in Dormann et al. study fistula formation in $10 \%$, chest pain and GERD in 10\%, and aspiration and pneumonia in 20\%. Yakoub, compared to plastic and metal stents and found mortality with metallic stent was lower $1.7 \%$ and lower perforation $1.4 \%$ and reduced migration of $6 \%$ [31].

Knyrim concluded that metal stents are more cost effective with no fatal complications and reduced hospital stay. Complications in our study post stenting are comparable to other studies and many patients got benefit of stents. Therefore we recommend use of metallic stents in late oesophageal malignancy as palliation. It can be used prior to radiotherapy where it will make oesophageal passage patent which may otherwise get occluded by edema caused by radiotherapy.

\section{Conclusion}

Self expanding metallic stents are invaluable in advanced oesophageal cancer for palliation and alleviation of symptoms and better quality of life. Patients prior to chemoradiotherapy may get benefit of stenting making oesophageal passage patent which may otherwise get occluded by edema caused by radiotherapy. Further research is needed to quantify the use of metallic stent in advanced esophageal malignancies.

\section{References}

[1] Chen, W., Zheng, R., Zhang, S., Zeng, H., Fan, Y., Qiao, Y. and Zhou, Q. (2014) Esophageal Cancer Incidence and Mortality in China, 2010. Thoracic Cancer, 5, 343-348. http://dx.doi.org/10.1111/1759-7714.12100

[2] Balazs, A., Galambos, Z. and Kupcsulik, P.K. (2009) Characteristics of Esophagorespiratory Fistulas Resulting from Esophageal Cancers: A Single-Center Study on 243 Cases in a 20-Year Period. World Journal of Surgery, 33, 9941001. http://dx.doi.org/10.1007/s00268-009-9988-3

[3] Homs, M.Y., Steyerberg, E.W., Eijkenboom, W.M., Tilanus, H.W., Stalpers, L.J., Bartelsman, J.F., van Lanschot, J.J., Wijrdeman, H.K., Mulder, C.J., Reinders, J.G., Boot, H., Aleman, B.M., Kuipers, E.J. and Siersema, P.D. (2004) Single-Dose Brachy-Therapy versus Metal Stent Placement for the Palliation of Dysphagia from Oesophageal Cancer: Multicenter Randomized Trial. Lancet, 364, 1497-1504. http://dx.doi.org/10.1016/S0140-6736(04)17272-3

[4] Biere, S.S., Maas, K.W., Cuesta, M.A., et al. (2011) Cervical or Thoracic Anastomosis after Esophaguectomy for Cancer: A Systematic Review and Metaanalysis. Digestive Surgery, 28, 29-35. http://dx.doi.org/10.1159/000322014

[5] Saluja, S.S., Ray, S., Pal, S., et al. (2012) Randomized Trial Comparing Side-to-Side Stapled and Hand-Sewn Esophagogastric Anastomosis in Neck. Journal of Gastrointestinal Surgery, 16, 1287-1295. http://dx.doi.org/10.1007/s11605-012-1885-7

[6] Briel, J.W., Tamhankar, A.P., Hagen, L., et al. (2004) Prevalence and Risk Factors for Ischemia, Leak and Stricture of Esophageal Anastomosis: Gastric Pull-Up versus Colon Interposition. Journal of the American College of Surgeons, 198, 536-541. http://dx.doi.org/10.1016/j.jamcollsurg.2003.11.026

[7] Lang, H., Piso, P., Stukenborg, C., et al. (2000) Management and Results of Proximal Anastomotic Leak in a Serie of 1114 Total Gastrectomies for Gastric Carcinoma. European Journal of Surgical Oncology, 26, 168-171. http://dx.doi.org/10.1053/ejso.1999.0764

[8] Rodella, L., Laterza, E., De Manzoni, G., et al. (1998) Endoscopic Clipping of Anastomotic Leakages in Esophagogastric Surgery. Endoscopy, 30, 453-456. http://dx.doi.org/10.1055/s-2007-1001307

[9] García-Moreno, J.L., Suárez Grau, J.M., Gómez Bravo, M.A., et al. (2007) Closure of Gastrocutaneous Fistula Using Endoscopic Biological Glue Injection. Rev EspEnferm Dig, 99, 676-677.

[10] Baron, T.H. (2001) Expandable Metal Stents for the Treatment of Cancerous Obstruction of the Gastrointestinal Tract. The New England Journal of Medicine, 344, 1681-1687. http://dx.doi.org/10.1056/NEJM200105313442206 
[11] Radecke, K., Gerken, G. and Treichel, U. (2005) Impact of a Self-Expanding, Plastic Esophageal Stent on Various Esophageal Stenoses, Fistulas, and Leakages: A Single-Center Experience in 39 Patients. Gastrointestinal Endoscopy, 6, 812-818. http://dx.doi.org/10.1016/s0016-5107(05)00290-7

[12] Freeman, R.K., Ascioti, A.J. and Wozniak, T.C. (2007) Postoperative Esophageal Leak Management with the Polyflex Esophageal Stent. The Journal of Thoracic and Cardiovascular Surgery, 133, 333-338. http://dx.doi.org/10.1016/j.jtcvs.2006.10.008

[13] Al-Haddad, M., Craig, C.A., Odell, J., Pajaro, O. and Wallace, M.B. (2007) The Use of Self-Expandable Plastic Stents for Non-Malignant Esophago-Pleural Fistulas. Diseases of the Esophagus, 20, 538-541. http://dx.doi.org/10.1111/j.1442-2050.2007.00704.x

[14] Ott, C., Ratiu, N., Endlicher, E., Rath, H.C., Gelbmann, C.M., Schölmerich, J. and Kullmann, F. (2007) Self-Expanding Polyflex Plastic Stents in Esophageal Disease: Various Indications, Complications, and Outcomes. Surgical Endoscopy, 21, 889-896. http://dx.doi.org/10.1007/s00464-006-9067-x

[15] Pennathur, A., Chang, A.C., McGrath, K.M., Steiner, G., Alvelo-Rivera, M., Awais, O., et al. (2008) Polyflex Expandable Stents in the Treatment of Esophageal Disease: Initial Experience. The Annals of Thoracic Surgery, 85, 1968-1972. http://dx.doi.org/10.1016/j.athoracsur.2008.01.095

[16] Johnsson, E., Lundell, L. and Liedman, B. (2005) Sealing of Esophageal Perforation or Ruptures with Expandable Metallic Stents: A Prospective Controlled Study on Treatment Efficacy and Limitations. Diseases of the Esophagus, 18, 262-266. http://dx.doi.org/10.1111/j.1442-2050.2005.00476.x

[17] Fischer, A., Thomusch, O., Benz, S., von Dobschuetz, E., Baier, P. and Hopt, U.T. (2006) Nonoperative Treatment of 15 Benign Esophageal Perforations with Self-Expandable Covered Metal Stents. The Annals of Thoracic Surgery, 81, 467-472. http://dx.doi.org/10.1016/j.athoracsur.2005.08.047

[18] Tuebergen, D., Rijcken, E., Mennigen, R., Hopkins, A.M., Senninger, N. and Bruewer, M. (2008) Treatment of Thoracic Esophageal Anastomotic Leaks and Esophageal Perforations with Endoluminal Stents: Efficacy and Current Imitations. Journal of Gastrointestinal Surgery, 12, 1168-1176. http://dx.doi.org/10.1007/s11605-008-0500-4

[19] Leers, J.M., Vivaldi, C., Schäfer, H., Bludau, M., Brabender, J., Lurje, G., et al. (2009) Endoscopic Therapy for Esophageal Perforation or Anastomotic Leak with a Self-Expandable Metallic Stent. Surgical Endoscopy, 23, $2258-2262$. http://dx.doi.org/10.1007/s00464-008-0302-5

[20] Pisani, P., Parkin, D.M., Bray, F. and Ferlay, J. (1999) Estimates of the Worldwide Mortality from 25 Cancers in 1990. International Journal of Cancer, 83, 18-29. http://dx.doi.org/10.1002/(SICI)1097-0215(19990924)83:1<18::AID-IJC5>3.0.CO;2-M

[21] Stein, H.J. and Siewert, J.R. (2004) Improved Prognosis of Resected Esophageal Cancer. World Journal of Surgery, 28, 520-525. http://dx.doi.org/10.1007/s00268-004-7417-1

[22] Tian, D., Wen, H.Y. and Fu, M.Y. (2016) Comparative Study of Self-Expanding Metal Stent and Intraluminal Radioactive Stent for Inoperable Esophageal Squamous Cell Carcinoma. World Journal of Surgical Oncology, 14, 18. http://dx.doi.org/10.1186/s12957-016-0768-x

[23] Katsanos, K., Sabharwal, T. and Adam, A. (2010) Stenting of the Upper Gastrointestinal Tract: Current Status. CardioVascular and Interventional Radiology, 33, 690-705. http://dx.doi.org/10.1007/s00270-010-9862-6

[24] Park, J.G., Jung, G.S., Oh, K.S. and Park, S.J. (2010) Double-Layered PTFE-Covered Nitinol Stents: Experience in 32 Patients with Malignant Esophageal Strictures. CardioVascular and Interventional Radiology, 33, 772-779. http://dx.doi.org/10.1007/s00270-009-9718-0

[25] Brierley, J.D. and Oza, A.M. (1998) Radiation and Chemotherapy in the Management of Malignant Esophageal Strictures. Gastrointestinal Endoscopy Clinics of North America, 8, 451-463.

[26] Johnson, E., Enden, T., Noreng, H.J., Holck-Steen, A., Gjerlaug, B.E., Morken, T., Johannessen, H.-O. and Drolsum, A. (2006) Survival and Complications after Insertion of Self-Expandable Metal Stents for Malignant Oesophageal Stenosis. Scandinavian Journal of Gastroenterology, 41, 252-256. http://dx.doi.org/10.1080/00365520500206350

[27] Homann, N., Noftz, M.R., Klingenberg-Noftz, R.D. and Ludwig, D. (2008) Delayed Complications after Placement of Self-Expanding Stents in Malignant Esophageal Obstruction: Treatment Strategies and Survival Rate. Digestive Diseases and Sciences, 53, 334-340. http://dx.doi.org/10.1007/s10620-007-9862-9

[28] Lowe, A.S. and Sheridan, M.B. (2004) Esophageal Stenting. Seminars in Interventional Radiology, 21, 157-166. http://dx.doi.org/10.1055/s-2004-860874

[29] Yakoub, D., Fahmy, R., Athanasiou, T., Alijani, A., Rao, C., Darzi, A. and Hanna, G.B. (2008) Evidence-Based Choice of Esophageal Stent for the Palliative Management of Malignant Dysphagia. World Journal of Surgery, 32, 1996-2009. http://dx.doi.org/10.1007/s00268-008-9654-1

[30] Dormann, A.J., Eisendrath, P., Wigginghaus, B., Huchzermeyer, H. and Devière, J. (2003) Palliation of Esophageal Carcinoma with a New Self-Expanding Plastic Stent. Endoscopy, 35, 207-211. http://dx.doi.org/10.1055/s-2003-37252 
[31] Knyrim, K., Wagner, H.J., Bethge, N., Keymling, M. and Vakil, N. (1993) A Controlled Trial of an Expansile Metal Stent for Palliation of Esophageal Obstruction Due to Inoperable Cancer. New England Journal of Medicine, 329, 1302-1307. http://dx.doi.org/10.1056/NEJM199310283291803 